\section{Cine peruano y violencia: Realidad y representación. Análisis histórico de La boca del lobo'}

\author{
Jorge Valdez Morgan
}

\section{Introducción}

E 1 cine peruano sobre el conflicto ar-

E mado interno ha intentado representar un periodo histórico del cual es, también, parte. Las complejas relaciones entre el filme y la sociedad que las ha producido y recibido, en este caso la sociedad peruana inserta en el proceso de violencia más grave de su historia, han configurado y en algunos casos determinado elementos importantes de la realización cinematográfica. Temas como la intencionalidad de los realizadores, las representaciones fílmicas de los diferentes grupos que conformaron el conflicto o de algunos hechos paradigmáticos, la utilización del cine como caja de resonancia y la percepción del público son factores importantes por analizar. El cine peruano sobre violencia política se ha valido de dichos preceptos básicos al momento de realizar sus películas, no solo por ser una constante ya existente en un sector del cine peruano, sino además porque es un sistema de aná-

1 Este artículo es una síntesis de la tesis de licenciatura en historia, sustentada por el autor en la Pontificia Universidad Católica del Perú. En ella se analiza la mayoría de los filmes sobre el conflicto armado interno, así como el devenir histórico del cine peruano de las últimas dos décadas. Para mayores referencias y una bibliografía ampliada véase Valdez Morgan, Jorge. "Imaginarios y mentalidades del conflicto armado interno en el Perú, 1980-2000. Una aproximación historiográfica al cine peruano sobre violencia política". Tesis de licenciatura. Lima: PUCP, 2005. 
lisis social muy útil cuando se quiere representar un contexto de violencia o de crisis. La riqueza de lo audiovisual permite, asimismo, en pocos segundos, transmitir una cantidad asombrosa de información que si la trasladamos a un texto ocuparía numerosas páginas de un libro.

Un filme contiene una gran variedad de ideas destinadas a un público, se le transmite a través de la pantalla mediante representaciones que forman parte de un imaginario común. En parte radica allí la posibilidad comunicativa del cine, en que se establece una relación recíproca entre el objeto y el sujeto, sin uno de estos la comunicación no existiría, y ambos son necesarios para lograr una comprensión cabal del acercamiento histórico a los filmes. El historiador Pierre Sorlin lo plantea de la siguiente manera:

El cine transmite representaciones y esquemas sociales; corta fragmentos del mundo exterior, que constituye en unidades continuas, los filmes, que impone al público. Cualquiera que sea el periodo considerado, la investigación histórica debe concentrarse, en primer lugar, en los medios utilizados para alcanzar al público; dicho de otro modo, en la legibilidad. ¿Cuáles son los procedimientos de exposición admitidos, tolerados, reprobados? ¿Qué convenciones forman una- nimidad y qué otras pasan por aberrantes o revolucionarias? ¿Cómo aborda el cine al universo sensible, siguiendo qué reglas lo divide, cómo encadena las imágenes y los sonidos, qué coherencia busca?" 2

El cine es un acto comunicativo en el cual se establecen una serie de imaginarios comunes que en su conjunto, el filme completo, representa un modo de pensar, una mentalidad. A lo largo de este artículo explicaremos las bases metodológicas del uso del cine como fuente histórica, explicaremos el devenir histórico del conflicto armado interno en el Perú y analizaremos uno de los filmes más paradigmáticos sobre el tema: La boca del lobo (Francisco Lombardi, 1988), con la finalidad de exponer qué imaginarios y mentalidades compartió parte de la sociedad peruana con respecto al conflicto armado interno (1980-2000).

\section{El cine como fuente histórica}

Poco después de finalizada la Segunda Guerra Mundial, en 1947, apareció un libro publicado por la Princeton University Press, bajo el título original From Caligari to Hitler: A Psychological History of the German Film. Así, Sigfried Kracauer, conocido crítico cinematográfico alemán, sentaría las ba-

2 SORLIN, Pierre. Sociología del cine: La apertura para la historia del mañana. México: Fondo de Cultura Económica, 1985, p. 187. 
ses de su teoría sobre el filme desde el punto de vista de análisis psicológico social e histórico. Hoy en día la investigación de Kracauer, si bien ha sido ampliamente superada, aún se considera el inicio de una larga lista de títulos proveniente de países como Italia, Francia, España, Estados Unidos e Inglaterra, y sin duda Brasil, Argentina, Chile y México. Sin embargo, es en la década de 1960 que los estudios sobre historia y cine cobran una mayor importancia al establecerse nuevas tendencias de análisis, ligadas a los estudios académicos y a las inquietudes políticas de la época. A partir de esa década encontramos a Marc Ferro, Pierre Sorlin, Jean Luc Godard, David Wenden, Nicholas Pronay, Richard Taylor, Jeffrey Richards, Tony Aldgate, Stephan Solezel, Martin Wissenschaflichen, José María Caparrós Lera, Luis Ángel Hueso, Martin Jackson, John O'Connor, Peter Burke, Peter C. Rollins y Robert Rosenstone, entre otros, así como numerosas revistas y centros de investigación. Gracias a los estudios realizados desde esos años, sea a partir de aproximaciones y contextos de estudio distintos, el cine ha pasado de ser considerado un pasatiempo y un arte menor por los científicos sociales, a un objeto de estudio extremadamente complejo, una fuente para el análisis histórico y social contemporáneo.
Uno de estos autores, Marc Ferro, es quien ha acuñado uno de los modos de análisis más completos, según lo explica Francesco Casetti. El análisis de Ferro consta de cuatro partes, que son cuatro modos de cómo el cine representa la realidad: a través de los contenidos, a través del estilo, a través de la actuación sobre la sociedad y a través de la lectura que se haga de él. ${ }^{3}$ De esta manera, tanto los campos propios del filme, como el guión o las imágenes filmadas son tomados en cuenta dentro del estudio; así como los textos y testimonios de las reacciones externas del filme, como las críticas o las entrevistas. El primero de los modos es el que Ferro toma más en cuenta, y de donde realiza su teoría del cine como contraanálisis social. ${ }^{4} \mathrm{El}$ historiador francés afirma que si bien la representación puede ser positiva o negativa, siempre esta va a contener incongruencias y lapsus donde la sociedad muestra lo que realmente sabe, aunque no lo quiera confesar. ${ }^{5}$

Por su parte, los historiadores peruanos no han tratado en lo absoluto al cine como un factor por considerar dentro de sus estudios de historia, contemporánea o no, y si bien algunos lo han mencionado, nunca han llevado a cabo investigaciones académicas usándolo como fuente. El historiador que

3 CASETTI, Francesco. Teorías del cine. 1945-1990. Madrid: Cátedra, 1994, pp. 148-149.

4 FERRO, Marc. Historia contemporánea y cine. Barcelona: Ariel, 1995, pp. 31-38.

5 Ibídem, p. 148. 
más interés ha demostrado por el cine, tanto a nivel personal como académico, es Jorge Basadre. ${ }^{6}$

Sin embargo, los investigadores que más han aportado a la historia del cine peruano y a su análisis son los del campo de las ciencias de la comunicación. Dentro de esa línea, hay trabajos importantes y hasta fundamentales, desde reseñas históricas hasta diccionarios. ${ }^{7}$

\section{El conflicto armado interno ${ }^{8}$}

El conflicto empieza formalmente con el inicio de la llamada "lucha armada" por parte del Partido Comunista del Perú - Sendero Luminoso (PCP-SL), el 17 de mayo de 1980, día de las primeras elecciones generales en diecisiete años en el Perú. El PCP-SL, facción maoísta del Partido Comunista del Perú desde 1970,9 liderada por Abimael Guzmán Reinoso, desarrolló un accionar subversivo y terrorista que produjo el 53,68 por ciento de los muertos totales del conflicto. ${ }^{10}$ Este dato diferencia al caso peruano del resto de conflictos internos de América Latina, donde fueron las fuerzas del orden las que provocaron el mayor número de víctimas y se consagran como los perpetradores casi exclusivos de violaciones a los derechos humanos (DDHH).

El periodo comprendido entre 1980 y 1993 fue el más violento y traumático de todo el conflicto armado interno. La cantidad de muertos y desaparecidos reportados a la Comisión de la Verdad y la Reconciliación (CVR) du-

6 Revisar: MACERA, Pablo. Conversaciones con Jorge Basadre. 2. edición. Lima: Mosca Azul, 1979, pp. 88-89; BASADRE, Jorge. Historia de la República del Perú. Tomo XVI. Lima: Editorial Universitaria, 1972, pp. 194-199; Equivocaciones. Ensayos sobre literatura penúltima. Lima: Ausonia, 2003 [1928]; La vida y la bistoria. 2. edición. Lima: Industrial Gráfica, 1981 [1975], p. 95.

7 Véase: BEDOYA, Ricardo. 100 años de cine en el Perú: Una bistoria crítica; Lima: Universidad de Lima, 1995; Un cine reencontrado. Diccionario ilustrado de las películas peruanas. Lima: Universidad de Lima, 1997; CARBONE, Giancarlo. "En busca del cine peruano". Contratexto 9. Lima: Universidad de Lima, 1995, pp. 79-86; El cine en el Perú: 1897-1950. Testimonios. Lima: Universidad de Lima, 1991; El cine en el Perú: 1950-1972. Testimonios. Lima: Universidad de Lima, 1993; LEÓN FRÍAS, Isaac. "El cine peruano. A paso de cojo". La Gran Ilusión 7. Lima: Universidad de Lima, primer semestre de 1997, p. 98-103; "La experiencia del cine militante latinoamericano en los años 60 y 70". Lienzo 12. Lima: Universidad de Lima, diciembre de 1991, pp. 229-233; WIENER, Christian. "El cine peruano en los noventa. La historia sin fin". La Gran Ilusión 5. Lima: Universidad de Lima, segundo semestre de 1995, pp. 96-104.

8 Un compendio bibliográfico bastante exhaustivo sobre el tema del conflicto armado interno lo encontramos en STERN, Peter. Sendero Luminoso: an annotated bibliography of the shining path guerrilla movement 1980-1993. New Mexico: SALAM Secretariat - University of New Mexico, 1997.

9 Sobre el PCP-SL, véase: Comisión de la Verdad y Reconciliación. Informe final, pp. 23-98 [en línea]. $<$ http://www.cverdad.org.pe/ifinal/index/.php>.

10 Comisión de la Verdad y Reconciliación. Informe final, p. 23. [en línea]. <http://www.cverdad.org. pe/ifinal/index/.php>. 
rante 1980 y 1993 representa casi el 90 por ciento de todo el conflicto, unas 21.572 personas, y según los estimados realizados por la CVR el número de muertos y desaparecidos en esta primera parte del conflicto llegaría a 63.352 de los 69.280 del total. ${ }^{11}$ Durante este periodo no solo murieron más personas, sino ocurrieron más atentados, matanzas, ejecuciones extrajudiciales y violaciones a los DDHH en general. Los años con más muertos y desaparecidos, 1983 y 1984, también están comprendidos dentro de esta parte, con 2.256 y 4.086, respectivamente.

El primer gran hito mediático de un hecho de violencia fue el asesinato de ocho periodistas en el poblado ayacuchano de Uchuraccay, el 26 de enero de 1983. Dichas imágenes marcaron también el interés de muchos realizadores cinematográficos por el contexto del conflicto, y es claro que su impacto en Lima fue significativo. Los directores Francisco Lombardi ${ }^{12}$ y Alberto Durant $^{13}$ aseguran que fue con la noticia de la matanza de Uchuraccay que empezaron a elaborar proyectos cinematográficos relacionados con el tema del conflicto armado interno.

En 1984 otra agrupación, pero esta vez proveniente de la nueva izquierda peruana y de la experiencia guerrillera latinoamericana, el Movimiento Revolucionario Túpac Amaru (MRTA), se alza en armas. Poco después, ocurre otro hito de violencia, la llamada matanza de los penales el 18 y 19 de junio de 1986. Los senderistas de los penales de Lurigancho, en Lima, y Santa Bárbara y El Frontón en el Callao, se amotinaron el 18 de junio. La respuesta de las fuerzas del orden fue devastadora, y se calcula que murieron más de 200 reclusos.

En la segunda mitad de la década de los ochenta ocurrió un despliegue nacional de la violencia, el PCP-SL abrió frentes en Puno, Junín y el valle del Huallaga, mientras que priorizó los asesinatos selectivos de autoridades en Lima. El MRTA abrió un frente guerrillero en el departamento de San Martín en 1987 y organizó una exitosa campaña publicitaria que fue aprovechada por los opositores del gobierno.

Por otra parte, se desarrollaron trabajos de inteligencia en la Dirección contra el Terrorismo (Dircote), al formarse el Grupo Especial de Inteligencia (GEIN) que se dedicaría al seguimiento y espionaje con la finalidad de capturar a los líderes de las organizaciones subversivas. Mientras tanto, la

11 Comisión de la Verdad y Reconciliación. Informe final. Compendio estadístico, p. 82 [en línea]. $<$ http://www.cverdad.org.pe/ifinal/index/.php>.

12 Entrevista con Francisco Lombardi, 22 de diciembre del 2004.

13 Entrevista con Alberto Durant, 17 de noviembre del 2004. 
espiral de la violencia causó estragos a nivel nacional, sucesos tristemente célebres como el enfrentamiento en Molinos entre miembros del MRTA y del ejército en 1988, el ataque al puesto policial de Uchiza por miembros del PCP-SL en 1989, la aparición del Comando Rodrigo Franco, el desarrollo de la comunidad senderista de Raucana en las afueras de Lima, las desapariciones de estudiantes de la Universidad Nacional del Centro por parte de agentes del Estado, la aparición del Grupo Colina y sus acciones en Barrios Altos y en la Universidad Nacional Guzmán y Valle, la fuga de presos del MRTA del penal de máxima seguridad Miguel Castro Castro en 1990, el atentado en la calle Tarata en Miraflores el 16 de julio de 1992 y el asesinato de María Elena Moyano, dirigente vecinal del distrito de Villa El Salvador, el 15 de febrero del mismo año. En 1989 y 1990 se encuentra el segundo pico de violencia, con 2.400 y 2.327 muertos, respectivamente. ${ }^{14}$

Dentro de ese contexto de crisis y caos, el 12 de setiembre de 1992, Abimael Guzmán es capturado en Lima. El principal líder del MRTA, Víctor Polay Campos, ya había sido detenido por segunda vez en 1991; el golpe fue fatal para el movimiento, y significó la dis- minución radical de asesinatos, desapariciones $^{15}$ y atentados por parte del PCP-SL, así como su paulatina derrota en zonas rurales.

Sin embargo, el fin real de la guerra no llevó a que el Estado actuara de acuerdo con los planes de pacificación o reconstrucción nacional. A partir del golpe del 5 de abril de 1992 por parte del entonces presidente Alberto Fujimori, y del apoyo de la cúpula militar, el estado de derecho y la defensa de los DDHH se vieron gravemente afectados, pasando de una aparente democracia a una real dictadura. El Grupo Colina, por ejemplo, continuó realizando acciones paramilitares y de amedrentamiento a opositores del gobierno, se llevó a cabo un operativo militar llamado 'Aries' en Huánuco en 1994, en el cual se produjo una focalizada pero sistemática violación a los derechos humanos, sobre todo desapariciones forzadas y ejecuciones extrajudiciales. ${ }^{16}$ Mientras esto sucedía, la figura de Vladimiro Montesinos se fortalecía en el gobierno, primero como asesor de Fujimori y luego como asesor del Servicio de Inteligencia Nacional, lugar desde el cual organizó una red de espionaje dedicada a obtener información tanto de enemigos como aliados políticos. Por último, se empe-

\footnotetext{
14 Comisión de la Verdad y Reconciliación. Informe final. Compendio estadístico. [Versión electrónica], p. 82 [en línea]. <http://www.cverdad.org.pe/ifinal/index/.php>.

15 Ibídem, p. 82.

16 Ibídem, p. 83.
} 
zó a gestar lo que luego sería el sistema organizado de corrupción gubernamental más grande de la historia del Perú, lo que incluyó no solo el robo de dinero del erario público, sino la total utilización de los poderes del Estado a favor del régimen, incluyendo a algunas empresas privadas como los canales de televisión, entre otros. El gobierno fujimorista elaboró la Constitución en 1993, la cual fue sometida a referéndum y ratificada, en la que se daba la posibilidad a una reelección inmediata. Fujimori, sin embargo, se presentó en el año 2000 a una segunda reelección en medio de un contexto de estancamiento económico y de denuncias de todo calibre en contra del gobierno.

La aparición de un video donde se ve a Montesinos sobornando a un congresista de oposición para que se traslade a la bancada oficialista desató una crisis moral y política en el régimen. Ante el aparente derrumbamiento del régimen luego del mensaje presidencial de Alberto Fujimori donde se convocaba a nuevas elecciones y el cierre del SIN, se produjo una huida bastante organizada y premeditada por parte del presidente, el cual se refugió en Japón, desde donde emitió una carta de renuncia.

\section{Análisis del filme La boca del lobo}

\section{Ficha técnica}

- Estreno: 1 de diciembre de 1988. Director: Francisco J. Lombardi.

- Guión: Giovanna Pollarolo, Augusto Cabada.

- Productora: Producciones Inca Films S.A., Tornasol Films (Madrid), Felipe Degregori, Francisco J. Lombardi.

- Actores: Gustavo Bueno, Toño Vega, José Tejada, Gilberto Torres, Berta Pagaza, Aristóteles Picho. Duración: 123 minutos.

\section{Análisis del argumento}

Si bien parte de la crítica cinematográfica calificó a La boca del lobo como un filme de aventuras que usó el argumento de Socos únicamente para sostener la historia de ficción, ${ }^{17}$ es obvio, revisando el contexto en el cual se produjo y llevando a cabo un análisis de los mensajes contenidos en el argumento, que el filme tenía una clara intención detrás de la historia, mostrar al público un hecho paradigmático del conflicto armado interno con la finalidad de que tome partido en contra de la guerra sucia desatada. Es decir, buscaba concientizar a

17 BEDOYA, Ricardo. Un cine reencontrado... Lima: Universidad de Lima, 1997, pp. 279-280; entrevista con Ricardo Bedoya, 12 de octubre del 2004. 
la población para que rechace los planteamientos de ciertos sectores sobre el endurecimiento de las acciones contrasubversivas dentro del conflicto, sin importar el respeto de los DDHH. El director del filme, Francisco Lombardi, menciona que:

[El proyecto de la película] Se inicia porque... de lo que recuerdo, en ese momento... yo tenía la sensación de que el tema de Sendero Luminoso se veía desde las ciudades como una cosa ajena al país, a la sociedad, como una cosa que estaba pasando muy lejos, que tenía poco que ver con lo que pasaba en la vida de las ciudades, y me parecía que ese conflicto que cada vez se hacía más grande, era un conflicto que había que amplificar. $^{18}$

Sobre este mismo tema, Augusto Cabada, guionista del filme, mencionó ante la interrogante de si La boca del lobo es un filme de concientización:

Sí, yo creo que eso es, exactamente, incluso te contaba que antes habíamos querido hacer una historia completamente ficticia, te lo contaba porque eso prueba que nuestra intención primigenia era sensibilizar, hacer una película que sensibilice sobre algo que nos parecía muy importante en ese momento, que había que decirlo, que había que mostrarlo, pero no sabíamos cómo, no teníamos el vehículo, la historia, y finalmente fue Socos el que nos proveyó un poco de ese marco narrativo, de ese pretexto narrativo, donde perfectamente se podían vehiculizar todos esos ingredientes sobre los cuales habíamos discutido tanto tiempo. ${ }^{19}$

Otra motivación para la realización del filme fue mostrar el tema del conflicto armado interno en el cine, pues hasta ese momento no existía ninguna película que tocara este punto. ${ }^{20}$

\section{Contexto de la realización}

Los primeros proyectos del filme, alrededor de 1985, se basaron en historias de ficción hasta que el director y los guionistas Augusto Cabada y Giovanna Pollarolo decidieron tomar el tema de la matanza de Socos como punto de partida. Para la época, realizar un filme sobre el conflicto armado interno presentaba muchas dificultades propias de un contexto de guerra interna, como la imposibilidad de filmar en las zonas de emergencia o de contar con el apoyo de las fuerzas del orden. Inclusive, Augusto Cabada recuerda que en un principio el proyecto cinematográfico fue realizado en secreto:

18 Entrevista con Francisco Lombardi, 22 de diciembre del 2004.

19 Entrevista con Augusto Cabada, 22 de octubre del 2004.

20 Ibídem. 
Naturalmente, todo esto empezamos a trabajarlo en secreto, y con cierto temor, claro, era el gobierno de Alan García, Alan García tenía una relación ambigua, o al menos así lo percibíamos nosotros, con los militares. (...) Y en ese contexto hacer esa película podía ser una provocación, no sabíamos si el gobierno lo iba a ver con buenos ojos... en esa época existía la famosa Coproci, que podía darte el paso o no, darte el beneficio o no, había exhibición obligatoria entonces, son mecanismos que podían convertirse en una especie de censura. ${ }^{21}$

Otro de los problemas fue el desconocimiento general de lo que era el PCP-SL tanto en su ideología como en su accionar. Es por ello que los guionistas se dirigieron a Ayacucho para realizar una investigación en el campo mismo del conflicto alrededor del año 1987.22

La filmación duró ocho semanas y se llevó a cabo en el poblado de Estique, en la sierra de Tacna, durante 1987 y 1988. El lugar fue elegido porque no presentaba los problemas de la zona de conflicto, al menos para esos años la guerra interna no se desenvolvía en la zona. No se contó el argumento del filme a los pobladores que actuaron como extras, debido a que el proyecto seguía siendo considerado secreto. Inclusive el hermetismo permitió que se contara con apoyo de algunas instituciones armadas, como la Fuerza Aérea o el Ejército, que de haber estado al tanto del tema no hubieran aceptado apoyar la historia y la intención de los realizadores.

\section{Contexto del estreno}

Cuando la película estuvo finalizada, fue enviada a la Comisión de Promoción Cinematográfica (Coproci). El filme no recibió en un principio el certificado de exhibición, pero tampoco le fue negado. Coproci conservó la cinta sin explicación alguna y esta fue llevada primero a Palacio de Gobierno y luego al Ministerio de Defensa. ${ }^{23}$ Luego de una semana, Francisco Lombardi fue citado al Ministerio de Defensa, donde se reunió con algunos generales:

\begin{abstract}
Y entonces a la semana me llamaron a mí, a este ministerio, y tuve una reunión con unos generales (...) la reunión fue una reunión relativamente cordial, digamos, no fue una amenaza ni una presión... hubo una sugerencia... la sugerencia era que la película no era conveniente darla en ese momento y que me solicitaban que postergara el estreno de la película. ${ }^{24}$
\end{abstract}

21 Ibídem.

22 Ibídem.

23 Entrevista con Francisco Lombardi, 22 de diciembre del 2004; entrevista con Augusto Cabada, 22 de octubre del 2004.

24 Entrevista con Francisco Lombardi, 22 de diciembre del 2004. 
El argumento de los militares era que la película mostraba un planteamiento ideológico peligroso y que alentaba a la subversión. Lo cierto es que no existen indicios que sugieran que el filme tuvo algún tipo de censura ni que el argumento o las imágenes filmadas estuvieran manipuladas por presiones externas ni internas. Si bien no se sabe qué comentó el presidente Alan García al ver el filme en Palacio de Gobierno, no hubo presiones políticas por parte del gobierno. El hecho de que el filme haya podido ser estrenado es más importante de lo que parece a simple vista, pues son pocos los filmes polémicos estrenados en contextos de conflicto armado interno en el mundo. Hasta la ruptura constitucional del 5 de abril de 1992, existieron presiones a los realizadores, mas no censuras a los filmes, y todos ellos pudieron ser estrenados.

Luego del estreno el filme, el 1 de diciembre de 1988, las Fuerzas Armadas alegaron que en el filme existía un ataque a dicha institución, una afirmación infundada pero comprensible dentro de la cultura de impunidad existente y también como una política grupal de no reconocer que se estaban llevando a cabo casos de violencia como los vistos en la película, realizados por un grupo de policías.

\section{Impacto en medios de comunicación}

La boca del lobo es el filme peruano sobre el que más se ha escrito y discutido en los medios de comunicación. El filme fue el primero que trató el tema del conflicto armado interno desde su inicio en 1980, por lo cual existía una expectativa en diversos sectores preocupados por los acontecimientos de violencia que estaban ocurriendo. $\mathrm{Su}$ posición crítica a las estrategias contrasubversivas provocó que sectores sociales y políticos que pedían una mayor mano dura en el conflicto se pronunciaran en diversos medios de comunicación, como recuerda el guionista Augusto Cabada:

\begin{abstract}
César Hildebrandt en su programa nos acusó de mostrar al ejército como una pandilla de salvajes, que es una película que favorece a la subversión, al senderismo, que denigra el esfuerzo de las Fuerzas Armadas. ${ }^{25}$
\end{abstract}

El crítico de cine e investigador Christian Wiener recuerda también el grado de incomprensión e ignorancia de algunos sectores de la prensa al criticar el filme:

El filme fue el más premiado del festival de La Habana. Acá en el Perú, me acuerdo que Roxana Canedo, que en esa épo-

25 Entrevista con Augusto Cabada, 22 de octubre del 2004. 
ca estaba en la conducción de Panora$m a$, dijo que eso demostraba la alianza entre Fidel Castro y Sendero Luminoso. ${ }^{26}$

$\mathrm{Al}$ poco tiempo, sectores de derecha y miembros de las Fuerzas Armadas dijeron públicamente que el filme distorsionaba la imagen de las Fuerzas Armadas y que se corría un grave peligro con su proyección. ${ }^{27}$ Ante una posible amenaza de censura, diversos medios masivos, como periódicos o revistas, dedicaron sendas páginas a entrevistar al director y a los guionistas, a reseñar positivamente el filme o publicar textos del director mismo sobre el tema. Tanto en las entrevistas y artículos publicados en las revistas Caretas $^{28}$ y $S i{ }^{29}$ en los suplementos Artes y Letras, ${ }^{30}$ Culturas $^{31}$ y $V S D^{32}$ del diario La República, y en el periódico mismo; 33 se plantean asuntos como la posible censura, las presiones y las críticas.

Otro factor importante es que el momento en que se estrena, a fines de 1988, la situación de violencia y de crisis interna era una de las peores en todo el conflicto armado. El contexto político y económico agudiza la crisis, pues solo meses antes, en setiembre de 1988, el gobierno lanza una serie de paquetes económicos de ajuste que desencadenan una hiperinflación nunca antes vista en la historia del Perú. En momentos de crisis como estos es

26 Entrevista con Christian Wiener, 19 de noviembre del 2004.

27 LOMBARDI, Francisco y otros. "En la boca del lobo". Debate. Vol X, núm. 53. Lima, noviembre-diciembre de 1988, p. 27. El dato hace referencia a la parte del artículo escrita por el general EP (r) Sinesio Jarama, titulado "Una imagen distorsionada".

28 LEÓN FRÍAS, Isaac. "La hora del lobo". Caretas (3 de octubre de 1988), pp. 68-69; "La boca del lobo". Caretas (12 de diciembre de 1988), p. 70; "¿Quién es el lobo? Habla Francisco Lombardi, director de la película". Caretas 1032 (14 de noviembre de 1988), p. 45; "Sendero de suicidios". Caretas 1032 (14 de noviembre de 1988), pp. 43-46.

29 BEDOYA, Ricardo. "Encuentro de lobos. La guerra sucia en el último filme de Lombardi". Sí (14 de noviembre de 1988), pp. 51-53; "La boca del lobo. Una oscura realidad". Sí (5 de diciembre de 1988), pp. 60-61.

30 CÁRDENAS, Federico de. "Francisco Lombardi habla de La boca del lobo: "Es la mejor acabada de mis películas"' [Entrevista con Francisco Lombardi]. Artes y Letras, suplemento dominical de La República, primera semana de diciembre de 1988, pp. 2-3.

31 "Se pueden hacer muchas cosas, pero falta dinero". (Entrevista con Giovanna Pollarolo). Culturas, suplemento de Artes y Letras. Suplemento dominical de La República, segunda semana de diciembre de 1988), p. 6.

32 CHÁveZ TORO, Carlos. "Lobo, iqué estás haciendo...!". VSD, suplemento de La República, 9 de diciembre de 1988, pp. 6-7.

33 BALBI, Mariela. "La boca del lobo, una historia sobre la violencia". (Entrevista con Francisco Lombardi). pp. 13-15; MIRÓ QUESADA, Roberto. "La boca (machista) del lobo". La República (9 de diciembre de 1988), p. 21. 
común que el interés por tocar el tema en medios de comunicación masivos aumente, y sobre todo en el cine, donde el asunto puede ser tratado desde un punto de vista que excede al periodístico, el de la ficción.

\section{Respuesta del público}

El debate y polarización sobre el tema de La boca del lobo contribuyó a generar expectativa en el público cinematográfico local. El filme, hasta el día de hoy, es uno de los más taquilleros de la historia del cine peruano, con alrededor de un millón de espectadores. ${ }^{34}$ Si bien es cierto que una película peruana siempre despierta expectativas, el delicado tema tocado en La boca del lobo despertó un gran interés no solo por ver el filme, sino por comentarlo y sentar una posición sobre él. Junto a La ciudad y los perros, Gregorio o Juliana es la película local que más peruanos han visto ${ }^{35}$ o que más les ha gustado, en parte por la constante repetición que ha tenido en canales de televisión abierta, donde es de proyección obligada cuando se realizan ciclos de cine peruano.

\section{Mentalidades e imaginarios sobre el conflicto armado interno en La boca del lobo}

\section{Imaginarios del PCP-SL}

En esta película los senderistas son construidos a partir de la amenaza que representan, y su ausencia fue también una parte importante en la creación de una situación de tensión y amenaza sufrida por los protagonistas, pero la decisión de la ausencia trascendió el ámbito cinematográfico, y refleja significativamente el desconocimiento que se tenía del PCP-SL aún en la segunda mitad de la década de 1980.

Si bien para el estreno del filme, diciembre de 1988, ya se contaba con mayor información del PCP-SL y el conocimiento sobre este grupo aumentaría con el pasar del tiempo gracias a los estudios académicos y a los hallazgos de los servicios de inteligencia de la policía nacional, en el momento de elaboración del guión aún era casi imposible trazar un personaje senderista verosímil, por lo cual se optó por no presentarlo. 36

\footnotetext{
34 NIEZEN, Cecilia. "Función imposible". El Comercio (28 de febrero del 2005). (http://www.elcomercioperu.com.pe/EdicionImpresa/Html/2005-02-26/impEconomia0265233.html).

35 PROTZEL, Javier. “¿Dónde vas? Al cine. Breve historia de las salas de cine”. Debate. Vol. XVII, núm. 85 Lima, noviembre-diciembre de 1995, p. 54.

36 Entrevista con Augusto Cabada, 22 de octubre del 2004.
} 
Imaginarios de los agentes del Estado

La boca del lobo presentó por primera vez a los policías en el contexto de la guerra interna. Si bien en los hechos reales en los cuales se basa el filme, la matanza de Socos, los perpetradores son policías de la Guardia Civil, en el filme no se deja en claro si son miembros del ejército o de la policía, pues su indumentaria y los transportes que utilizan son de las Fuerzas Armadas. Esto se explica por el hecho de considerar forzadamente a los policías dentro de un grupo más grande, el comprendido también por las Fuerzas Armadas, los cuales también tenían en su haber una gran cantidad de violaciones a los DDHH desde su ingreso formal en el conflicto en 1983. Para la fecha de elaboración del guión las Fuerzas Armadas se han convertido, junto con el PCP-SL, en uno de los principales actores del conflicto, por lo cual los realizadores deciden hacer una conjunción entre lo que serían miembros policiales y del ejército, de tal manera que todos los grupos se vean representados en la pantalla y la crítica del discurso les incluya. ${ }^{37}$

Su condición de agentes del Estado provenientes de zonas urbanas o de Lima se contrapone a la de los campe- sinos del pueblo de Chuspi, donde establecen su puesto de comando. Los realizadores de La boca del lobo buscaron identificar al espectador con el grupo de policías para que de esta manera se vean reflejados en la idiosincrasia y en los discursos racistas, y sentara una posición sobre ellos. ${ }^{38}$ En ese sentido los agentes del Estado en este filme no solo cumplen una función dentro de la historia, sino que sirven como vehículo de comunicación entre el espectador y el filme.

Los policías de La boca del lobo son utilizados para exponer las contradicciones sociales entre la capital y las provincias, entre los ricos y los pobres, entre los blancos y los cholos, a través de un discurso racista y de actitudes abusivas frente a la población. ${ }^{39}$

Si bien este aspecto excede la caracterización de los policías o de los agentes del Estado en general, es bien comprendido en el discurso racista limeño/costeño general con respecto a las provincias y a los espacios rurales. Por otra parte, el discurso militar en sí es presentado a través del personaje del teniente Iván Roca en dos oportunidades, la primera luego de convocar a una reunión del pueblo en la plaza y la segunda casi al final del filme, al re- 
criminar a sus subalternos ante las dudas por la matanza. Ambos discursos se asemejan mucho a los de algunos militares a lo largo del conflicto armado interno, por ejemplo en las entrevistas con Telmo Hurtado Hurtado, responsable de la matanza de Accomarca en 1985.40

\section{Imaginarios de la población}

La comunidad campesina de La boca del lobo es un personaje casi tan ausente como lo es el PCP-SL en el mismo filme, pero no por causa del desconocimiento, sino por la perspectiva de otro grupo, el de los policías, y está destinada a representar las diferencias sociales existentes en el contexto del conflicto. De esta manera los pobladores quechuahablantes son presentados como extraños, callados, desconfiados y poco colaboradores con los policías, los cuales no llegan a entender su idiosincrasia. La decisión de configurar a este grupo con estas características fue provocada por la intención de los guionistas de plantear el problema de la desigualdad social pero no adentrarse en un análisis o interpretación de lo que se podría llamar el problema del indio, lo cual habría causado un desbalance en la historia argumental y cu- ya complejidad es imposible de retratar en un filme.

Una de las secuencias en el filme que más información nos da acerca de este abismo social entre los pobladores y los policías presentado por los realizadores ocurre cuando Roca convoca a una reunión en la plaza del pueblo. Allí, luego de llevar a rastras a toda la población de Chuspi, Roca toma la palabra y amenaza a la población, para luego obligarlos a cantar el himno nacional. En ese momento, los pobladores de Chuspi, quechuahablantes pero que entienden y se pueden comunicar en castellano, y analfabetos en su mayoría, son obligados a asumir su papel de ciudadanos ante una bandera de un Estado que no los representa y que no los ha incorporado a un proyecto nacional. Uno de los momentos más logrados del filme ocurre cuando los policías insultan y empujan a los pobladores que no saben el himno nacional de su país.

\section{Conclusiones}

La boca del lobo es un filme de concientización con una fuerte carga política. Esto se ve tanto en la intención expresa del director Francisco Lombardi y de los guionistas Giovanna Polla-

40 CHÁVEZ TORO, Carlos. "Lobo, iqué estás haciendo...!". VSD, suplemento de La República. Lima, 9 de diciembre de 1988, pp. 6-7. 
rolo y Augusto Cabada, lo cual se trasladó a la concepción inicial del filme, la elaboración de su guión y el tratamiento visual; es decir, en el texto fílmico en conjunto. El difícil contexto histórico que vivió el Perú alrededor de 1988 contribuyó a aumentar la carga política del filme, pues mientras algunos sectores de la derecha y las FFAA argumentaban que el filme era prosenderista y alentaba a la subversión, gran parte de la prensa escrita lo apoyó, basándose en la libertad de expresión y en que no expresaba alguna idea a favor del PCP-SL. En realidad, el análisis de los medios de prensa estuvo mucho más cerca a la realidad que el de los agentes del Estado y los grupos políticos de derecha, pues si bien La boca del lobo asume una posición clara, esta no es antimilitarista y menos prosenderista, sino en contra de la guerra sucia que se estaba llevando a cabo de manera desatada en la década de los ochenta.

Otra intención de los autores del filme fue representar la realidad de la manera más fiel posible, lo cual es una constante en el cine sobre el conflicto armado interno en el Perú. Esta decisión, por obvia que pueda parecer, no es necesaria en sí misma, pues existen muchos casos en que una alegoría es preferida a un relato verosímil a la hora de representar un tema político contemporáneo, sobre todo en contextos de libertad de expresión restringida. Si bien el Perú cuenta con uno de esos casos, el de Malabrigo de Alberto Du- rant, su puesta en escena no obedeció a una amenaza de censura, sino a motivos puramente cinematográficos. En La boca del lobo se escogieron diversos hechos históricos de los años ochenta, siendo el principal la matanza perpetrada por agentes del Estado en el poblado ayacuchano de Socos, para recrear un argumento de ficción. La necesidad vista por los autores de contar con el relato más verosímil posible los llevó a realizar una investigación en archivos, bibliotecas y en la zona de conflicto. Gracias a esta intención y al acierto de los realizadores en el tratamiento del tema, es en La boca del lobo que vemos muchos de los imaginarios y mentalidades que marcaron el conflicto armado interno, al menos durante toda la década de 1980. Si bien se trata del primer filme sobre el tema en ocho años desde que se inició el conflicto, esto no conlleva necesariamente a que en un filme se condensen una serie de imaginarios y mentalidades de una época tan turbulenta y caótica como lo fue este periodo del conflicto armado interno. En La boca del lobo, la verosimilitud del relato, la presencia de un acertado discurso crítico a la guerra sucia, la exposición de la problemática social detrás de la violencia, y el desarrollo de los personajes y espacios brindan una serie de datos históricos que ayudan a esclarecer no tanto los datos ya conocidos como fechas, lugares o nombres, sino las ideas, mentalidades, estereotipos y hasta los sentimientos. 
La expectativa del estreno y la difícil situación política de la época determinaron que el filme sea uno de los más vistos de la historia del Perú. Su éxito en las salas de cine y en la televisión local también evidencia la aceptación crítica del público a los mensajes expuestos en la pantalla.

Si retomamos el comienzo de este artículo, afirmamos que el cine establece una relación recíproca entre el objeto y el sujeto, y que los mensajes expuestos en la pantalla son aprobados o no por lo espectadores en la medida en que se adecuan a los imaginarios sociales, pero que a la vez $-y$ en esto radica la reciprocidad cinematográfica- el mensaje cinematográfico pasa a ser parte de los imaginarios sociales de los espectadores, imaginarios que ya se han transformado luego del fin de la película. Los filmes alteran nuestro conocimiento del pasado al convertirse en parte de él, se convierten en parte de la historia de las sociedades inmediatas, y por lo tanto una fuente histórica extremadamente compleja y valiosa. Estudiar y preservar la memoria filmada, y en esto incluimos largometrajes, cortometrajes y documentales, puede ayudar a dar más luces sobre la historia política, social y cultural del siglo XX en el Perú. Es necesario que dichos vestigios se difundan y conserven.

\section{Bibliografía y fuentes}

\section{Películas}

Largometraje principal

- La boca del lobo (Francisco Lombardi, 1988).

Largometrajes complementarios

- Alias La Gringa (Alberto Durant, 1991).

- La vida es una sola (Marianne Eyde, 1993).

- Coraje (Alberto Durant, 1998).

- Sangre inocente (Palito Ortega Matute, 2000).

- Paloma de papel (Fabricio Aguilar, 2003).

- Abisa a los compañeros (Felipe Degregori, 1980).

- Malabrigo (Alberto Durant, 1986).

- Ni con Dios ni con el diablo (Nilo Pereira del Mar, 1990).

- Anda, corre, vuela... (Augusto Tamayo, 1995).

\section{Archivos y bibliotecas}

- Biblioteca Central de la Pontificia Universidad Católica del Perú (PUCP).

- Biblioteca de Ciencias Sociales PUCP.

- Centro de Documentación de la Facultad de Ciencias Sociales PUCP. 
- Centro de Documentación de la Facultad de Comunicaciones - Universidad de Lima.

- Centro de Información para la Memoria Colectiva y los Derechos Humanos - Defensoría del Pueblo.

\section{Entrevistas realizadas}

- Entrevista con Ricardo Bedoya. Lima, 12 de octubre del 2004.

- Entrevista con Augusto Cabada. Lima, 22 de octubre del 2004.

- Entrevista con Giovanna Pollarolo. Lima, 16 de noviembre del 2004.

- Entrevista con Alberto Durant. Lima, 17 de noviembre del 2004.

- Entrevista con Christian Wiener. Lima, 19 de noviembre del 2004.

- Entrevista con Francisco Lombardi. Lima, 22 de diciembre del 2004.

\section{Libros:}

BASADRE, Jorge. Equivocaciones. Ensayos sobre literatura penúltima. Lima: Ausonia, 2003 [1928].

—_. La vida y la bistoria. 2. a edición. Lima: Industrial Gráfica, 1981 [1975].

_. Historia de la República del Perú. T. XVI. Lima: Editorial Universitaria, 1972.

BEDOYA, Ricardo. Entre fauces y colmillos. Las películas de Francisco
Lombardi. Huesca: Festival de Cine de Huesca, 1997.

- Un cine reencontrado. Diccionario ilustrado de las películas peruanas. Lima: Universidad de Lima, 1997.

—. 100 años de cine en el Perú: una bistoria crítica. Lima: Universidad de Lima, 1995.

BURKE, Peter. Visto y no visto. El uso de la imagen como documento bistórico. Barcelona: Crítica, 2001.

CAPARRÓS LERA, José María. La guerra de Vietnam, entre la bistoria y el cine. Barcelona: Ariel, 1998.

—_. 100 películas sobre historia contemporánea. Barcelona: Alianza Editorial, 1997.

CARBONE, Giancarlo. El cine en el Perú: 1950-1972. Testimonios. Lima: Universidad de Lima, 1993.

—. El cine en el Perú: 1897-1950. Testimonios. Lima: Universidad de Lima, 1991.

CASETTI, Francesco. Teorías del cine. 1945-1990. Madrid: Cátedra, 1994.

—. El film y su espectador. Madrid: Cátedra, 1989.

Comisión de la Verdad y Reconciliación. Informe final (Perú: 19802000). Tomo I. El proceso, los 
hechos, las víctimas. Exposición general. Lima: UNMSM/PUCP, 2004.

- Informe final. Lima: CVR, 2003. [en línea]. <http://www.cverdad.org.pe/ifinal/index/.php>.

- Yuyanapaq. Para recordar. Relato visual del conflicto armado interno en el Perú, 1980-2000. Lima: Pontificia Universidad Católica del Perú, Fondo Editorial, 2003.

Desco. Violencia politica en el Perú: 1980 - 1988. Tomos I y II. Lima: Desco, 1989.

FERRO, Marc. Historia contemporánea y cine. Barcelona: Ariel, 1995.

GORRITI, Gustavo. Sendero: Historia de la guerra milenaria en el Perú. 4. edición. Lima: Apoyo, 1990.

HUESO, Ángel Luis. El cine y el siglo XX. Barcelona: Ariel, 1998.

JIMÉNEZ, Benedicto. Inicio, desarrollo y ocaso del terrorismo en el Perú: el ABC de Sendero Luminoso y el MRTA, ampliado y comentado. Lima: Sanki, 2000.

KRACAUER, Siegfried. De Caligari a Hitler. Una bistoria psicológica del cine alemán. Barcelona: Paidós, 1995.

- Teoría del cine: La redención de la realidad física. Barcelona: Paidós, 1989.
MANRIQUE, Nelson. El tiempo del miedo. La violencia política en el Perú 1980-1996. Lima: Congreso de la República, Fondo Editorial, 2002.

PÉREZ, María Dolores (coord.). La memoria filmada: América Latina a través de su cine. Madrid: IEPALA, 2002.

ROLLINS, Peter. Hollywood: el cine como fuente histórica. La cinematografía en el contexto social, político y cultural. Buenos Aires: Fraterna, 1987.

ROSENSTONE, Robert A. El pasado en imágenes: El desafío del cine a nuestra idea de bistoria. Barcelona: Ariel, 1997.

- Romantic Revolutionary: A Biography of John Reed. Cambridge: Harvard University Press, 1990.

SADOUL, Georges. Historia del cine mundial: Desde los orígenes hasta nuestros dias. México: Siglo XXI, 1989.

SORLIN, Pierre. Cines europeos, sociedades europeas. Barcelona: Paidós, 1996.

- Sociología del cine: la apertura para la bistoria del mañana. México: Fondo de Cultura Económica, 1985.

STERN, Peter. Sendero Luminoso: an annotated bibliography of the shining path guerrilla movement 
1980-1993. New Mexico: SALAM Secretariat - University of New Mexico, 1997

STERN, Steve J. (ed.). Los senderos insólitos del Perú. Lima: IEPUNSCH, 1999.

\section{Artículos}

BALBI, Mariela. "La boca del lobo, una historia sobre la violencia”. (Entrevista con Francisco Lombardi). La República. Lima, 27 de noviembre de 1988, pp. 13-15.

BEDOYA, Ricardo. "Encuentro de lobos. La guerra sucia en el último filme de Lombardi”. Sí. Lima, 14 de noviembre de 1988, pp. 5153.

—. "La boca del lobo. Una oscura realidad". Sí. Lima, 5 de diciembre de 1988, pp. 60-61.

BUENO, Gustavo. "Soy un hombre de izquierda" (entrevista). VSD, suplemento de La República. Lima, 16 de diciembre de 1998, p. 12.

CARBONE, Giancarlo. "En busca del cine peruano". Contratexto 9. Lima: Universidad de Lima, 1995, pp. 79-86.

CÁRDENAS, Federico de. "Francisco Lombardi habla de La boca del lobo: 'Es la mejor acabada de mis películas"” [Entrevista con Francisco Lombardi]. Artes y Le- tras, suplemento dominical de La República. Lima, primera semana de diciembre de 1988, pp. 2-3.

Caretas. "¿Quién es el lobo? Habla Francisco Lombardi, director de la película". Caretas 1032. Lima, 14 de noviembre de 1988, p. 45.

—. "Sendero de suicidios". Caretas 1032. Lima, 14 de noviembre de 1988, pp. 43-46.

CHÁvez TORO, Carlos. "Lobo, iqué estás haciendo...!". VSD, suplemento de La República. Lima, 9 de diciembre de 1988, pp. 6-7.

CHÁvEZ, Rony. "El Conacine trabaja a sextas. Entrevista con Javier Protzel". Butaca Sanmarquina. Año 5, núm. 17. Lima, agosto del 2003, pp. 14-16.

COTLER, Andrés. "El cine peruano y Sendero Luminoso. La vida es una sola”. La Gran Ilusión 3. Lima: Universidad de Lima, primer semestre de 1994, pp. 98102.

FIJO, Alberto y Fernando GIL-DELGADO. "Conversación con Pierre Sorlin”. Filmbistoria Online. Vol. XI, núm. 1, febrero del 2001.

LEÓN FRÍAS, Isaac. "El cine peruano. A paso de cojo". La Gran Ilusión 7. Lima: Universidad de Lima, primer semestre de 1997, pp. 98103. 
-. "La experiencia del cine militante latinoamericano en los años 60 y 70". Lienzo 12. Lima: Universidad de Lima, diciembre de 1991, pp. 229-233.

- "La hora del lobo". Caretas. Lima, 3 de octubre de 1988, pp. 68-69.

—. "La boca del lobo". Caretas. Lima, 12 de diciembre de 1988, p. 70 .

—. "Abisa a los compañeros". Caretas. Lima, 14 de enero de 1980, p. 78 .

LOMBARDI, Francisco y otros. "En la boca del lobo". Debate. Vol. X, núm. 53. Lima, noviembre-diciembre de 1988, pp. 25-29.

MIRÓ QUESADA, Roberto. "La boca (machista) del lobo". La República. Lima, 9 de diciembre de 1988, p. 21.
NIEZEN, Cecilia. "Función imposible". El Comercio. Lima, 28 de febrero del 2005. [en línea]. <http:// www.elcomercioperu.com.pe/E dicionImpresa/Html/2005-02$26 /$ impEconomia 0265233. html>.

Quehacer. "Lombardi y la campaña contra La boca del lobo". Quebacer 57. Lima, febrero-marzo de 1989, pp. 108-109.

WIENER, Christian. "Miedos de guerra: cine nacional, violencia y derechos humanos". Butaca Sanmarquina. Año 4, núm. 14. Lima, diciembre del 2002, pp. 18-20.

_- "El cine peruano en los noventa. La historia sin fin". La Gran Ilusión 5. Lima: Universidad de Lima, segundo semestre de 1995, pp. 96-104. 